

\section{JURNAL SAINS DAN TEKNOLOGI}

JURNAL PENELITIAN DAN KARYA ILMIAH STMIK DHARMASRAYA

\section{Penerbit}

Lembaga Penelitian dan Pengabdian Kepada Masyarakat Sekolah Tinggi Manajemen Informatika dan Komputer Dharmasraya

\section{Pelindung}

Epri Yuldi, S.Kom, M.Kom (Ketua STMIK Dharmasraya)

\section{Penanggung Jawab}

Gunawan Ali, S.Kom, M.Kom (Ketua LPPM STMIK Dharmasraya)

\section{Pimpinan Redaksi}

Wahyu Prima, S.Kom, M.Kom

Sekretaris

Firmansyah Putra, S.Kom

\section{Bendahara}

Wulan Andang Purnomo, S.Pd, M.Kom

Dewan Editor

Adi Fitra Andikos, S.Kom, M.Kom (STMIK Dharmasraya) Raimon

Efendi, SAB, M.Kom (STMIK Dharmasraya)

Fauzi Tri Yuniko, S.Kom, M.Kom (STMIK Dharmasraya)

Moh. Rosyid Mahmudi, M.Si (STKIP Dharmasraya)

Estuhono, M.Pd (STKIP Dharmasraya)

\section{Alamat Redaksi \\ Kampus STMIK Dharmasraya}

Jln. Lintas Sumatera KM 18 Koto Baru

Dharmasraya, Sumatera Barat

Email: stmikdmr@gmail.com

Jurnal Sains dan Teknologi STMIK Dharmasraya merupakan Jurnal Penelitian dan Karya Ilmiah yang diterbitkan oleh LPPM STMIK Dharmasraya yang terbit dua kali setahun. Jurnal Sains dan Teknologi STMIK Dharmasraya menerima naskah ilmiah hasil penelitian, telaah, maupun review dalam bidang sains dan teknologi untuk dipublikasikan pada jurnal ini. Naskah yang diterima akan disunting dan dievaluasi. Penyuntingan dilakukan untuk keseragaman format tanpa mengubah maksud. 
RANCANG BANGUN APLIKASI PENDATAAN PENDUDUK NAGARI KOTO SALAK KABUPATEN DHARMASRAYA OLEH LILIK SUHERY. 1

SIMULASI GELOMBANG SEDERHANA MELALUI PERSAMAAN SINUS MENGGUNAKAN MATLAB DENGAN ARAH PENJALARAN RADIUS (DUA DIMENSI) OLEH MOH ROSYID MAHMUDI. 6

DESAIN BAHAN AJAR MULTIMEDIA INTERAKTIF DALAM BENTUK COMPACT DIST MULTIMEDIA INTERACTIF (CMI) PADA MATA KULIAH IPA SEKOLAH DASAR OLEH ESTUHONO. 12

PERANCANGAN DAN IMPLEMENTASI INTRUSION PREVENTION SYSTEM (IPS) SEBAGAI SECURITY JARINGAN DENGAN SNORT DI DINAS KEPENDUDUKAN DAN CATATAN SIPIL KOTA PADANG OLEH GUSRINO YANTO.

16

KAJIAN SISTEM PAKAR DAN FUZZY LOGIC DALAM PENENTUAN JURUSAN OLEH FAUZI TRI YUNIKO.

PENERAPAN METODE FORWARD CHAINING UNTUK MEMPREDIKSI HASIL PANEN PRODUKSI PERTANIAN KOMODITI SAWIT KABUPATEN DHARMASRAYA OLEH ADI FITRA ANDIKOS

DESAIN MEDIA BACA ANAK USIA DINI OLEH WULAN ANDANG PURNOMO. 36

IMPLEMENTASI TEKNOLOGI BARCODE SEBAGAI SUPPORT SYSTEM PADA APLIKASI POINT OF SALE (POS) OLEH GUNAWAN ALI 44 PENERAPAN METODE FUZZY ANALYTICAL HIERARCHY PROCESS (F-AHP) PADA SISTEM PENDUKUNG KEPUTUSAN PEMILIHAN RUMAH TINGGAL OLEH PURWANTI . 52

ANALISIS DAN PERANCANGAN JARINGAN NIRKABEL UNTUK IMPLEMENTASI SISTEM INFORMASI AKUNTANSI PERBANKAN OLEH RAIMON EFENDI 59 


\title{
PENERAPAN METODE FORWARD CHAINING UNTUK MEMPREDIKSI HASIL PANEN PRODUKSI PERTANIAN KOMODITI SAWIT KABUPATEN DHARMASRAYA
}

\author{
Adi Fitra Andikos \\ Sekolah Tinggi Manejemen Informatika dan Komputer (STMIK) Dharmasraya \\ Jln. Lintas Sumatera KM 18 Koto Baru, Dharmasraya 27681 \\ Email: Andicos_afa@yahoo.co.id
}

\begin{abstract}
Abstrak
Selama ini para transmigran di Indonesia terutama kabupaten dharmasraya memprediksi hasil produksi buah sawit hanya dengan cuaca. Salah satu bagian yang penting pada bidang pertanian pada umumnya adalah bagaimana seorang petani atau pemilik kebun dapat memperkirakan hasil produksi yang akan diperoleh pada saat panen. Prediksi atau analisa tentang hasil panen ini penting karena berhubungan dengan strategi pemasaran. Kesalahan dalam memprediksi hasil panen bisa berakibat patal pada hasil panen, karena buah kelapa sawit merupakan momoditas perkebunan yang tidak bisa disimpan lama. Berbeda dengan komoditi lain seperti karet, biji kopi, coklat yang bisa disimpan dalam waktu lama. prediksi hasil panen dengan menerapkan sistem pakar diharapkan dapat meningkatkan pendapatan dan harkat petani perkebunan serta para transmigran di Indonesia terutama kabupaten dharmasraya. Hasil penelitian menunjukkan bahwa para komoditi kabupaten dharmasraya mampu memprediksi hasil panen dengan baik.
\end{abstract}

Keywords: Sistem Pakar, Forward Chaining, Kelapa Sawit, Prediksi.

\section{Pendahuluan}

Salah satu penerapan AI yang sangat populer saat ini adalah Sistem Pakar. Dengan sistem pakar bisa membuat penggunaan secara luas knowledge yang khusus untuk penyelesaikan masalah tingkat manusia yang pakar. Seorang pakar adalah orang yang mempunyai keahlian dalam bidang tertentu, yaitu pakar yang mempunyai knowledge atau kemampuan khusus yang orang lain tidak mengetahui atau tidak mampu dalam bidang yang dimilikinya. Masalah-masalah yang dipecahkan melalui sistem pakar umumnya merupakan masalah yang sulit atau bahkan tidak dapat dipecahkan melalui teknik program konvesional. Program dari sistem pakar dibuat berdasarkan suatu himpunan aturan (rule) yang mampu menganalisis informasi mengenai suatu masalah spesifik serta analisis matematis dari masalah tersebut. Sistem ini memanfaatkan kemampuan penalaran (reasoning) untuk mencapai suatu kesimpulan. Kelapa sawit (elaeis quinesis jacq) sangat penting artinya bagi Indonesia. Selama kurun waktu 20 tahun terakhir kelapa sawit menjadi komoditas andalan ekspor dan komoditas yang diharapkan dapat meningkatkan pendapatan dan harkat petani perkebunan serta para transmigran di Indonesia.

Total investasi perkebunan kelapa sawit baru selama bulan April-September 2007 mencapai 7,7 triliun, sehingga berpotensi menyerap sedikitnya 93.000 tenaga kerja dan dapat menggerakkan perekonomian di pedesaan. Kelapa sawit merupakan komoditas yang mempunyai nilai strategis karena merupakan bahan baku utama pembuatan minyak makan. Sementara minyak makan merupakan salah satu dari 9 kebutuhan pokok bangsa Indonesia. Permintaan akan minyak makan di dalam dan luar negeri yang kuat merupakan indikasi pentingnya peranan komoditas kelapa sawit dalam perekonomian bangsa. Disamping untuk di produksi menjadi minyak makan, minyak kelapa sawit juga dikembangkan sebagai bahan baku untuk membuat bahan bakar biodiesel. Terobosanterobosan seperti ini menjadikan kebutuhan sawit pada masa mendatang akan semakin meningkat.

\section{Metodologi Penelitian}

Penyelesaian penelitian ini dilakukan dengan mengikuti kerangka kerja yang terdiri dari 7 tahapan. 


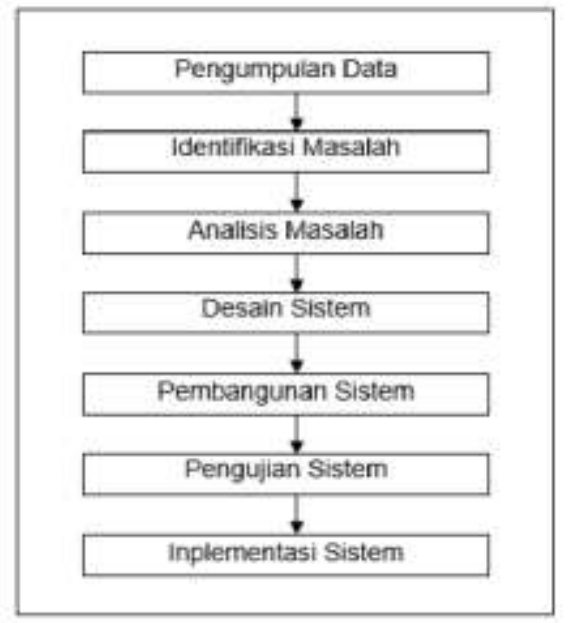

Gambar 1 Kerangka Penelitian

\section{Hasil dan Pembahasan}

Faktor yang mempengaruhi kelapa sawit yaitu faktor innate, faktor induce dan faktor enforce. Faktor innate adalah faktor yang terkait dengan genetic tanaman, bersifat mutlak dan sudah ada di dalam tanaman, faktor induce adalah faktor yang mempengaruhi ekspresi sifat genetik sebagai manifestasi faktor lingkungan yang terkait dengan keadaan buatan manusia, faktor enforce adalah faktor lingkungan/alam yang bersifat mendorong/menghambat pertumbuhan dan produksi tanaman, umumnya tidak dapat dikendalikan manusia secara langsung.

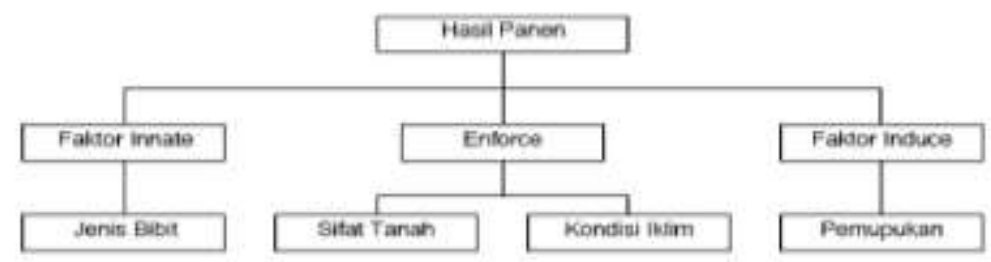

Gambar 2 Faktor Yang Mempengaruhi Pertumbuhan Kelapa Sawit

Sistem pada sistem pakar ini melayani tiga macam pengguna yaitu admin yang berhak mengelola sistem secara keseluruhan dan mengatur hak akses, pakar yang memasukkan pengetahuan ke dalam basis pengetahuan, dan petani yang memanfaatkan fasilitas konsultasi.

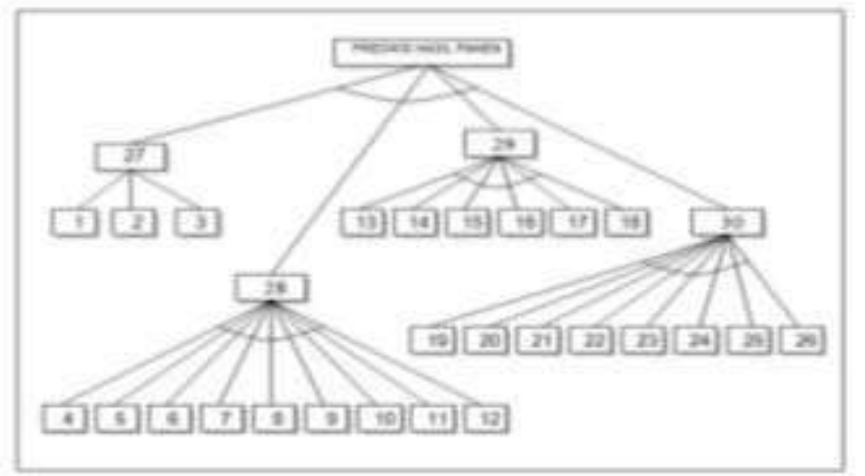

Gambar 3 Pohon Keputusan Prediksi Hasil Panen Kelapa Sawit

\section{Keterangan :}

1. Bibit kualitas baik (Tenera K1)

2. Bibit kualitas sedang (Tenera K2)

3. Bibit kualitas kurang (Tenera K3)

4. Lereng 19. Pupuk urea

5. Solun tanah 20. Pupuk ZA

6. Ketinggian air tanah

7. Tekstur tanah
16. Temperatur cuaca

17. Penyinaran matahari

18. Kelembaban udara

8. Struktur tanah

9. Konsistensi tanah 
ISSN: 2443-3470

Volume 1, No 1, Mei 2015| 6

10. Permeabilitas tanah

11. Keasaman tanah

12. Gambut

13. Curah hujan

14. Defisit air

15. Hari tanpa hujan

21. Pupuk RP

22. Pupuk TSP

maka proses akan melakukan pengulangan. Kalau data ditemukan maka proses akan dilanjutkan dengan menampilkan hasil prediksi.

\section{Jurnal Sains dan Teknologi}
23. Pupuk MOP
24. Pupuk kieserit
25. Pupuk abu janjang
26. Pupuk HGFB
27. Jenis Bibit
28. Sifat tanah
29. Parameter iklim
30. Pupuk

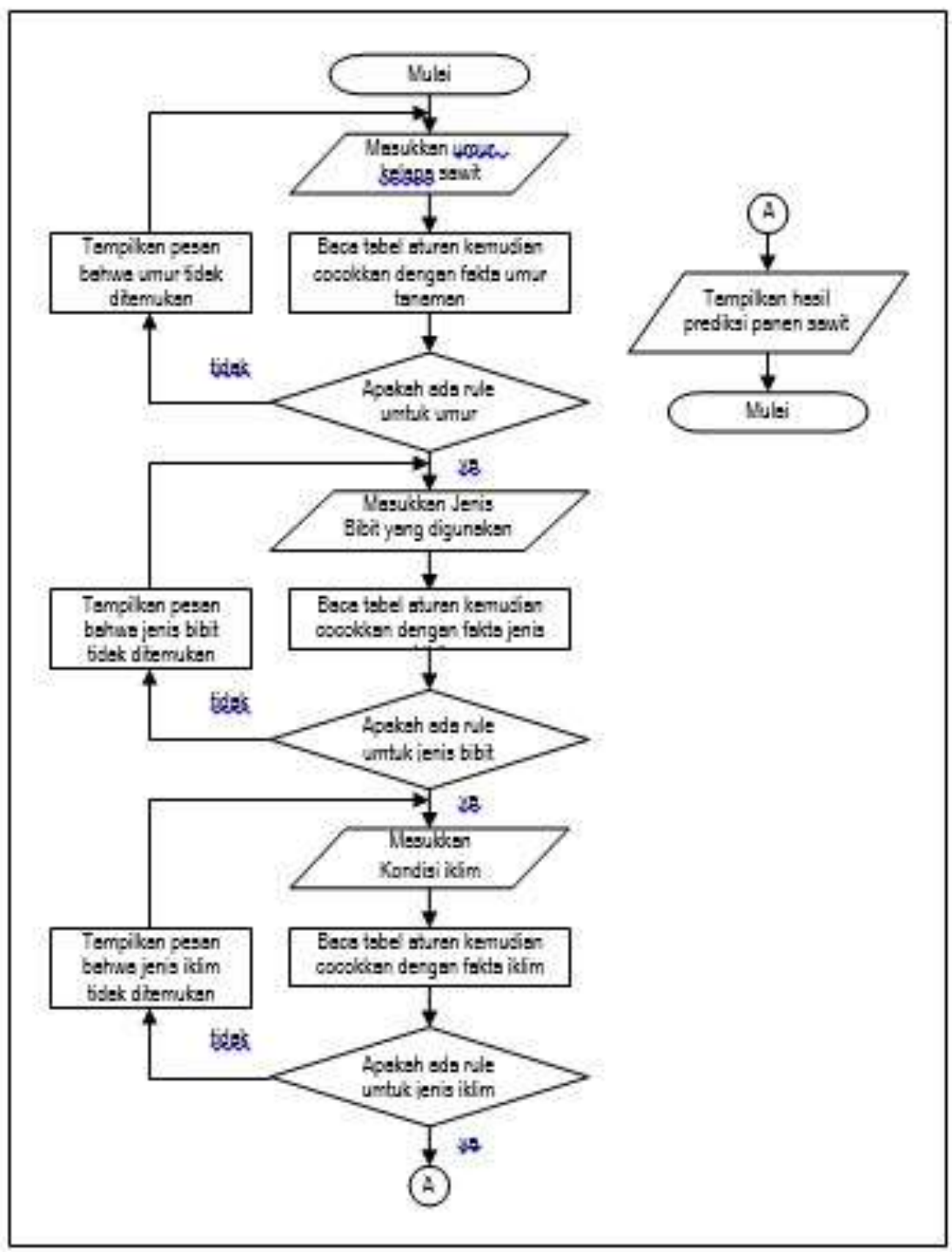

Gambar 4 Algorithma Inferensi Engine

Algoritma sistem pakar untuk memprediksi hasil panen sawit dapat dilihat pada gambar 3. Pada algorithma tersebut tampak ketika proses penelusuran dimulai pemakai diminta untuk memasukkan umur kelapa sawit. Selanjutnya sistem melakukan penelusuran pada rule untuk mencari fakta umur, kalau data ditemukan maka proses dilanjutkan untuk memasukkan data jenis bibit. Begitu seterusnya hingga semua faktor yang mempengaruhi hasil panen terlacak. Kalau data tidak ditemukan pada rule

Untuk memudahkan pengoperasian sistem ini maka, dirancang struktur program seperti pada Gambar 5 . 


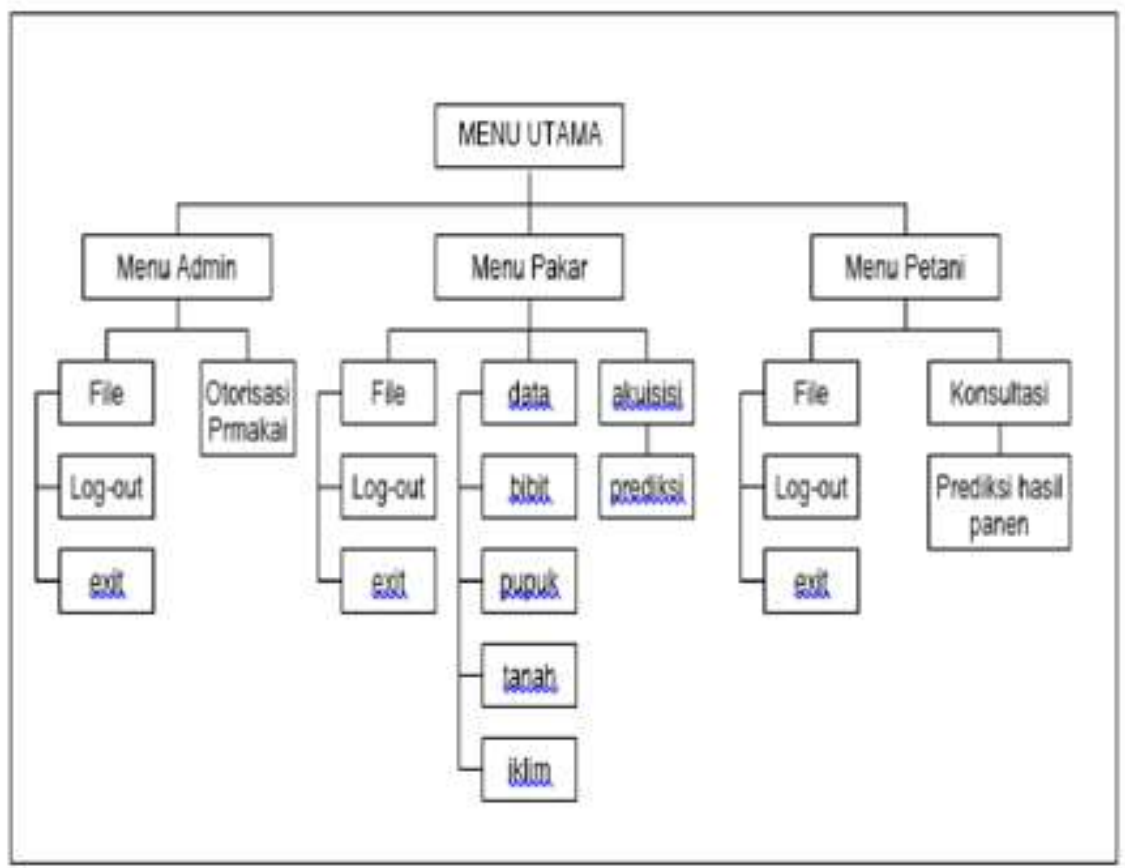

Gambar 5 Struktur Program

Form konsultasi dan prediksi hasil panen merupakan fasilitas yang disediakan untuk user petani, pada form ini petani diminta untuk memasukkan semua parameter yang disediakan. Dari data input tersebut maka sistem akan menampilkan hasil prediksi hasil panen yang akan dihasilkan. Selain parameter diatas, untuk memprediksi hasil panen juga harus dimasukkan tahun penanaman kelapa sawit dan tahun prediksi. Hal ini diperlukan untuk mengetahui umur tanaman tersebut. Karena hasil panen juga sangat dipengaruhi oleh umur tanaman. Bentuk tampilan dari form input data rule seperti pada gambar 6.

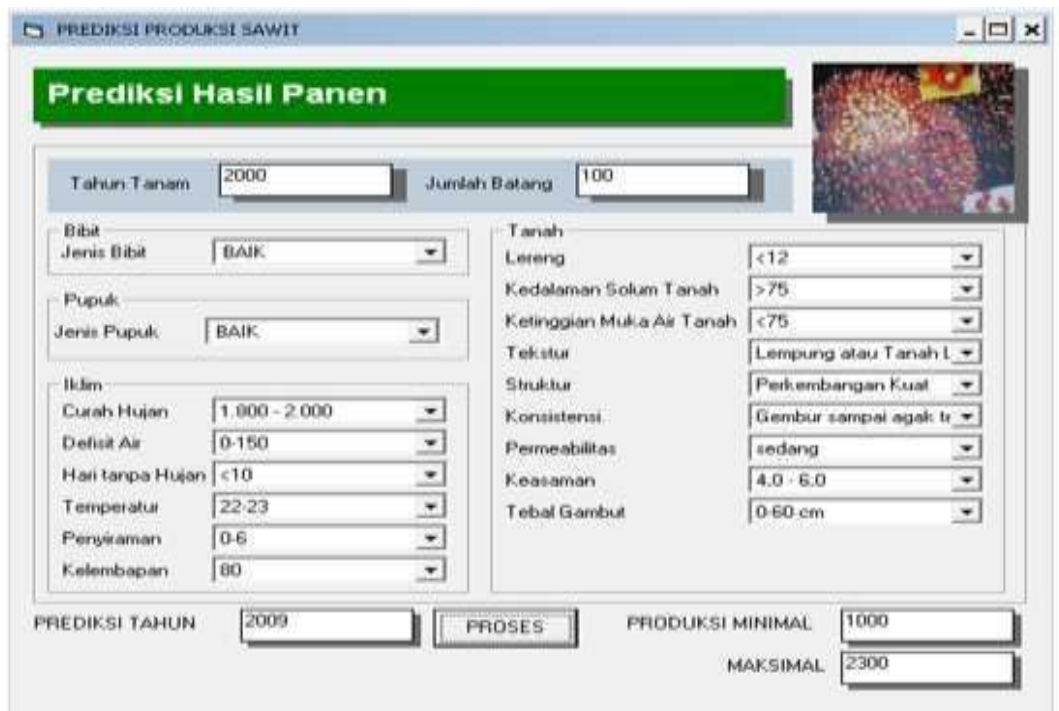

Gambar 6 Form Prediksi Hasil Panen

\section{Kesimpulan}

Ada tiga faktor yang sangat mempengaruhi pertumbuhan dan perkembangan kelapa sawit, yaitu faktor innate, faktor induce dan faktor enforce. Faktor Innate adalah faktor yang terkait dengan genetic tanaman, bersifat mutlak dan sudah ada di dalam tanaman, faktor Induce adalah faktor yang mempengaruhi ekspresi sifat genetik sebagai manifestasi faktor lingkungan yang terkait dengan keadaan buatan manusia, dan faktor enforce adalah faktor alam yang bersifat mendorong/menghambat pertumbuhan dan produksi tanaman, umumnya tidak dapat dikendalikan mausia secara langsung. Sistem pakar yang dirancang dapat melakukan prediksi hasil panen kelapa sawit berdasarkan data inputan yang 
terdiri dari umur tanaman, jenis bibit, jenis pupuk yang digunakan, jenis tanah dan kondisi iklim. Metode inferensi runut maju (fordward chaining) cocok digunakan untuk menangani masalah pengendalian (controling) dan peramalan (prognosis). Keluaran dari sistem ini adalah RataRata Berat Tandan (RBT) hasil panen kelapa sawit.

\section{Daftar Pustaka}

[1] Anita Desiani \& Muhammad Arhami (2006), “Konsep Kecerdasan Buatan”, Andi Yogyakarta, Yogyakarta.

[2] Arhami, Muhammad (2005), “Konsep Dasar Sistem Pakar”, Andi Yogyakarta, Yogyakarta

[3] Gufron (2009),"Rancangan sistem pakar untuk prediksi kualitas buah sawit"Jurnal voll.15 [4] Iyung Pahan (2007), "Panduan Lengkap Kelapa Sawit (Manajemen Agribisnis dari Hulu hingga Hilir”, Penebar Swadaya, Jakarta.

[5] Kusrini (2008), “Aplikasi Sistem Pakar", Andi Yogyakarta, Yogyakarta.

[6] Maruli Pardamean (2008), Panduan Lengkap Pengolahan Kebun dan Pabrik Kelapa Sawit”, Angromedis Pustaka, Jakarta.

[7] Sunarko (2007), "Petunjuk Praktis Budidaya dan Pengolahan Kelapa Sawit”, Agromedia Pustaka, Jakarta.

[8] Turban, E (2001), “Decision Support System and Intelegence System”, six edition, Prentice Hall International, Inc. New Jersey. 


\title{
TITLE OF THE PAPER, TIMES NEW ROMAN, 14 FONT SIZE, CENTER, BOLD, 100 CAPITAL LETTERSOR 2 LINES
}

\author{
First Autor ${ }^{1}$, Second Author ${ }^{2}$, Third Author ${ }^{3}$ \\ Institution/affiliation addres, telp/fax of \\ institution/affiliation e-mail: \\ xxxx@xxxx.xxx
}

\begin{abstract}
A well-prepared abstract enables the reader to identify the basic content of a document quickly and accurately, to determine its relevance to their interests, and thus to decide whether to read the document in its entirety. The Abstract should be informative and completely self-explanatory, provide a clear statement of the problem, the proposed approach or solution, and point out major findings and conclusions. The Abstract should be 100 to 150 words in length. The abstract should be written in the past tense. Standard nomenclature should be used and abbreviations should be avoided. No literature should be cited. The keyword list provides the opportunity to add keywords, used by the indexing and abstracting services, in addition to those already present in the title. Judicious use of keywords may increase the ease with which interested parties can locate our article.
\end{abstract}

Keywords: maximum 5 keywords from paper

\section{Introduction}

Paper size $210 \mathrm{~mm} \times 297 \mathrm{~mm}$ of A4 paper. Please save to MS Word templates directory. Use 10 point Times New Roman font. Single line spacing is mandatory. Try to avoid Underline or Bold within texts. Throughout the paper including text inside figures and tables must follow 10 Font size or larger.

Top margin is $30 \mathrm{~mm}$ while the left, right, and bottom margins are $25 \mathrm{~mm}$. Headings should be all left justified and numbering. Leave one line between headings and the first paragraph and no space before succeeding paragraphs. Indent the first line of the paragraph by $5 \mathrm{~mm}$. All text should be left and right justified. Footnotes and underlines are not allowed.

\section{Research Method}

Explaining research chronological, including research design, research procedure (in the form of algorithms, Pseudocode or other), how to test and data acquisition [1], [3]. The description of the course of research should be supported references, so the explanation can be accepted scientifically [2], [4]. Tables and Figures are presented center, as shown below and cited in the manuscript.

Figure 1.

Table 1. Basic Data Promethee

\begin{tabular}{c|c|c|c|c|c|c|}
\hline & $\mathrm{f}_{1}()$. & $\mathrm{f}_{2}()$. & $\ldots$ & $\mathrm{f}_{\mathrm{j}}()$. & $\mathrm{f}_{\mathrm{k}}()$. \\
\hline $\mathrm{a}_{1}$ & $\mathrm{f}_{1}\left(\mathrm{a}_{1}\right)$ & $\mathrm{f}_{2}\left(\mathrm{a}_{1}\right)$ & $\ldots$ & $\mathrm{f}_{\mathrm{j}}\left(\mathrm{a}_{1}\right)$ & $\mathrm{f}_{\mathrm{k}}\left(\mathrm{a}_{1}\right)$ \\
\hline $\mathrm{a}_{2}$ & $\mathrm{f}_{1}\left(\mathrm{a}_{2}\right)$ & $\mathrm{f}_{2}\left(\mathrm{a}_{2}\right)$ & $\ldots$ & $\mathrm{f}_{\mathrm{j}}\left(\mathrm{a}_{2}\right)$ & $\mathrm{f}_{\mathrm{k}}\left(\mathrm{a}_{2}\right)$ \\
\hline$\ldots$ & $\ldots$ & $\ldots$ & $\ldots$ & $\ldots$ & $\ldots$ \\
\hline \multirow{5}{*}{ Figure 1. } & $\mathrm{a}_{\mathrm{i}}$ & $\mathrm{f}_{1}\left(\mathrm{a}_{\mathrm{i}}\right)$ & $\mathrm{f}_{2}\left(\mathrm{a}_{\mathrm{i}}\right)$ & $\ldots$ & $\mathrm{f}_{\mathrm{j}}\left(\mathrm{a}_{\mathrm{i}}\right)$ & $\mathrm{f}_{\mathrm{k}}\left(\mathrm{a}_{\mathrm{i}}\right)$ \\
\hline$\ldots$ & $\ldots$ & $\ldots$ & $\ldots$ & $\ldots$ & $\ldots$ \\
\hline$\ldots$ & $\ldots$ & $\ldots$ & $\ldots$ & $\ldots$ \\
\hline
\end{tabular}

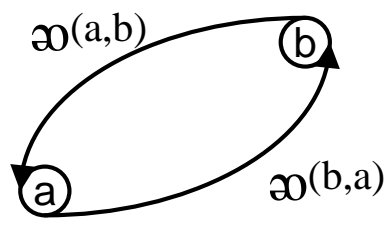

Node

\section{Results and Analysis}

In this section, it is explained the results of research and at the same time is given the comprehensive discussion. Results can be presented in figures, graphs, tables and others that make the reader understand easily [2], [5]. The discussion can be made in several sub-chapters.

\section{Conclusion}

Provide a statement that what is expected, as stated in the "Introduction" chapter can ultimately result in "Results and Discussion" chapter, so there is compatibility. Moreover, it can also be added the prospect of the development of research results and application prospects of further studies into the next (based on result and discussion). 


\section{References}

References are written in Vancouver style. Please use a consistent format for references - see examples below:

[1] Casadei D, Serra G, Tani K. Implementation of a Direct Control Algorithm for Induction Motors Based on Discrete Space Vector Modulation. IEEE Transactions on Power Electronics. 2007; 15(4): 769-777. (in this case Vol.15, Issues 4, and page 769-777)

[2] Calero C, Piatiini M, Pascual C, Serrano MA. Towards Data Warehouse Quality Metrics. Proceedings of the 3rd Intl. Workshop on Design and Management of Data Warehouses (DMDW). Interlaken. 2009; 39: 2-11. (in this case, city: Interlaken, year: 2009, Vol.39, page: 211)

[3] Yamin L, Wanming C. Implementation of Single Precision Floating Point Square Root on FPGAs. IEEE Symposium on FPGA for Custom Computing Machines. Napa. 2008: 226-232.

[4] Mohan N, Undeland TM, Robbins WP. Power Electronics. New York: John Wiley \& Sons. 2005 : 11-13.

[5] Ward J, Peppard J. Strategic planning for Information Systems. Fourth Edition. West Susse: John Willey \& Sons Ltd. 2007: 102-104.

[6] Mohan N, Undeland TM, Robbins WP. Power Electronics. New York: John Wiley \& Sons. 2005.

[7] Ward J, Peppard J. Strategic planning for Information Systems. Fourth Edition. West Susse: John Willey \& Sons Ltd. 2007.

[8] Rusdi M. A Novel Fuzzy ARMA Model for Rain Prediction in Surabaya. PhD Thesis. Surabaya: Postgraduate ITS; 2009.

[9] IEEE Standards Association. 1076.3-2009. IEEE Standard VHDL Synthesis Packages. New York: IEEE Press; 2009. 
Template 
Lembaga Penelitian dan Pengabdian Masyarakat STMIK Dharmasraya 